\title{
O QUE DIZEM OS ESTUDANTES SOBRE GÊNERO NÃO-BINÁRIO: UM ESTUDO COMPARATIVO NA UNIVERSIDADE FEDERAL DE SERGIPE E NA UNIVERSIADE DA MADEIRA
}

\author{
LO QUE DICEN LOS ESTUDIANTES SOBRE EL GÉNERO NO-BINARIO: UN \\ ESTUDIO COMPARATIVO EN LA UNIVERSIDAD FEDERAL DE SERGIPE Y LA \\ UNIVERSIDAD DE MADEIRA
}

\section{WHAT STUDENTS SAY ABOUT NON-BINARY GENDER: A COMPARATIVE STUDY AT THE FEDERAL UNIVERSITY OF SERGIPE AND THE UNIVERSITY OF MADEIRA}

RESUMO: Este artigo apresenta uma análise da subcategoria de gênero não-binário, no decurso de um estudo comparativo na Universidade da Madeira, UMa (Portugal) e na Universidade Federal de Sergipe, UFS (Brasil) sobre "Vozes dos estudantes universitários sobre a diversidade sexual e de gênero, sua relação com a coeducação e com a inovação pedagógica." Em termos metodológicos foi adotada uma abordagem qualitativa, com aplicação de um questionário com questões abertas e fechadas e o visionamento de um vídeo curto de enquadramento do tema. Foi feita a análise de conteúdo aos dados obtidos. Os resultados comparados mostram que ambos os ex-estudantes das duas universidades dizem ter conhecimento do conceito de gênero não-binário, embora os participantes na UMa apresentem resultados superiores. Tanto os ex-estudantes da UMa como os da UFS valorizam $\mathrm{o}$ conceito de gênero não-binário e reconhecem a necessidade de discuti-lo. Utilizam expressões idênticas quando fazem considerações valorativas sobre este conceito. No entanto verifica-se maior envolvimento dos ex-estudantes da Universidade Federal de Sergipe na discussão deste tema. Os participantes da UMa a afirmam que raramente participam em ações sobre o tema. Também se observa que a maioria dos ex-estudantes da UFS têm uma forte consciência dos constrangimentos que a vivência do conceito de gênero não-binário apresenta.

PALAVRAS-CHAVE: Educação. Diversidade. Gênero não-binário. Academia.

RESUMEN: Este artículo presenta un análisis de la subcategoría de género no binaria de un estudio comparativo en la Universidad de Madeira, UMa (Portugal) y la Universidad Federal de Sergipe, UFS (Brasil) sobre "Voces de estudiantes universitarios sobre la diversidad sexual y de género, su relación con la coeducación y la innovación pedagógica ”.

\footnotetext{
${ }^{1}$ Universidade da Madeira (UMA), Funchal - Portugal. Professor e Investigador sénior na área científica de Inovação Pedagógica. Membro Associado do Centro de Investigação em Educação. ORCID: https://orcid.org/0000-0003-3575-4366. E-mail: jbrazao@staff.uma.pt

${ }^{2}$ Universidade Federal de Sergipe (UFS), São Cristóvão - SE - Brasil. Professor Permanente do Programa de Pós-Graduação em Educação (PPGED), Departamento de Educação. Doutorado em Sociologia (UFS). ORCID: https://orcid.org/0000-0002-5562-0085. E-mail: diasalfrancio@academico.ufs.br
}

RPGE- Revista on line de Política e Gestão Educacional, Araraquara, v. 25, n. 3, p. 2886-2909, set./dez. 2021. e-ISSN: 1519-9029 DOI: https://doi.org/10.22633/rpge.v25i3.15680 
La metodología de esta investigación fue cualitativa. Se aplicó un cuestionario con preguntas abiertas y cerradas y el visionado de un video sobre el tema. Realizamos análisis de contenido sobre los datos obtenidos. Los resultados comparados muestran que ambos exalumnos de las dos universidades afirman conocer el concepto de género no binario, los participantes de la UMa presentan resultados superiores. Antiguos alumnos de la UMa y la UFS valoran el concepto de género no-binario y reconocen la necesidad de discutirlo. Usan expresiones idénticas al hacer consideraciones evaluativas sobre este concepto. Sin embargo, existe una mayor participación de los exalumnos de la Universidad Federal de Sergipe en la discusión de este tema. Los participantes de la UMa dicen que rara vez participan en acciones sobre el tema. También se observa que la mayoría de los exalumnos de la UFS son muy conscientes de las dificultades que presenta la vivencia del concepto de género nobinario.

PALABRAS CLAVE: Educación. Diversidad. Género no-binario. Academia.

ABSTRACT: This article presents an analysis of the non-binary gender subcategory of a comparative study at the University of Madeira, UMa (Portugal) and the Federal University of Sergipe, UFS (Brazil) on "Voices of university students on sexual and gender diversity, its relationship with co-education and pedagogical innovation." The methodology of this research was qualitative. We applied a questionnaire with open and closed questions and the viewing of a video on the subject. We performed content analysis on the data obtained. The compared results show that both former students from the two universities claim to know the concept of non-binary gender, UMa participants present superior results. Former UMa and UFS students value the concept of non-binary gender and recognize the need to discuss it. They use identical expressions when making evaluative considerations about this concept. However, there is greater involvement of former students from the Federal University of Sergipe in the discussion of this topic. UMa participants say they rarely participate in actions on the topic. It is also observed that most former UFS students are strongly aware of the difficulties that the experience of the non-binary gender concept presents.

KEYWORDS: Education. Diversity. Non-binary gender. Academy.

\section{Introdução}

Os indivíduos procuram incluir-se socialmente construindo o gênero a partir do que consideram os gêneros inteligíveis, que são os que apresentam coerência com a sua matriz cultural, na lógica da continuidade entre sexo, género e desejo, e prática reguladora, relações binárias e heterossexualidade compulsória (LOURO, 2003). Assim tornam-se pessoas com gêneros de valor e inserem-se nos grupos de identidades dominantes.

Mas a matriz cultural que desencadeia a eleição os gêneros inteligíveis faz com que alguns tipos de "identidades" não possam ter o direito de "existir", quando a construção do gênero não decorre do sexo ou as práticas do desejo não "decorrem" nem do "sexo" nem do “gênero" (LEMOS; ANDRADE; CARDOSO, 2020). 
O gênero não-binário apresenta-se como uma identificação à margem do sistema em vigor porque é compreendido fora do modelo binário, num discurso de descontinuidade face ao modelo padrão, considerado o determinante e único para a identificação dos indivíduos. Para Lemos, Andrade e Cardoso (2020), num estudo sobre subversão do gênero a partir de uma análise discursiva de publicações em weblogs, a não-binariedade de gênero apresenta-se como uma possibilidade no processo de identificação dos sujeitos como sendo nem masculina nem feminina, uma fusão de ambos os gêneros, ou ainda, a negação ou a não identificação com qualquer um dos gêneros. Pode então ser definida como algo fluído ou múltiplo, face aos discursos dos sujeitos, dos seus posicionamentos e das suas vivências. Nesse sentido, a não-binariedade é já uma construção de identidade de gênero porque congrega a expressão de gênero e a negação da dualidade do sistema binário.

A não-binariedade é uma forma de subversão do conceito de gênero. A diversidade de experiências não binárias são expressões de gênero que possibilitam a análise e a discussão sobre a desconstrução social do masculino ou feminino, que dá lugar a novas construções críticas da identidade.

O termo subversão de gênero surge então como processo contínuo de resistência dos sujeitos considerados identidades minoritárias na reinvenção da realidade que os oprime. A subversão representa ainda a desconstrução dos padrões de exclusão, impostos com base na dualidade masculino/feminino, homem/mulher e na heteronormatividade (CARDOSO; SOARES; LIMA, 2017).

Subverter essa lógica significa ir contra os diferentes discursos de poder. É ainda deparar-se com a possibilidade de ausência de identificação, ou de representatividade normativa, sobre as conceções e práticas da vivência do gênero. O corpo "performance" (BUTLER, 2013) é o ponto de interceção entre a subjetividade e as significações históricas e culturais apropriadas pelos sujeitos. Assim, a subversão do gênero é um mecanismo fundamental para produzir corpos performativamente inteligíveis e uma forma de resistência às diversas formas de violência e exclusão social a que os indivíduos que não expressam o seu gênero pelo padrão são regularmente sujeitos. Nesse sentido, é necessário colocar uma lente dissidente, não normativa, enquanto ato político sobre das questões de gênero, em conformidade com as influências dos estudos pós-identitários (DIAS; BRAZÃO, 2021).

As políticas sociais que tratam a inclusão social de gênero em Portugal e no Brasil têm produzido de forma diferenciada diretrizes para as organizações e instituições. No Brasil, apesar do direcionamento das políticas públicas recentes, a inclusão da perspectiva da diversidade sexual e de gênero na educação e na formação docente ainda não foi generalizada 
no pensamento educacional, nem se transversalizou na educação superior, nem na formação docente inicial (CARVALHO et al., 2017). Em Portugal, a Estratégia Nacional para a Igualdade e a Não Discriminação 2018-2030 "Portugal + Igual”, do XXI Governo Constitucional, apresentou em 2018 um "Plano de Ação de combate à discriminação em razão da Orientação sexual, Identidade e Expressão de género e Características sexuais". Algumas instituições do ensino superior em Portugal bem como no ensino não superior têm vindo a desenvolver trabalhos nesta área.

Urge olhar para as instituições educativas, tentando perceber como este tema é conhecido, discutido e se há iniciativas de inclusão da diversidade sexual e de gênero no meio acadêmico.

A discussão sobre o conceito de gênero não-binário insere-se no estudo comparativo na Universidade da Madeira, UMa (Portugal) e na Universidade Federal de Sergipe, UFS (Brasil) sobre "Vozes dos estudantes universitários sobre a diversidade sexual e de gênero, sua relação com a coeducação e com a inovação pedagógica" (BRAZÃO; OLIVEIRA; DIAS, 2021). O projeto de pós-doutoramento foi apresentado por Brazão (2021) ${ }^{3}$ e encontra-se publicado na plataforma TheBrain.com, sob orientação de Alfrancio Ferreira Dias, investigador e docente do Programa de Pós-doutoramento em Educação e Diversidade da Universidade Federal de Sergipe ${ }^{4}$.

Para este artigo consideramos a discussão do conceito de gênero não-binário a partir de três aspetos básicos: a) $\mathrm{O}$ conceito de gênero não-binário caracterizado como a variação dos modos de vivenciar o gênero, para além da polarização homem/mulher; b) A expressão de gênero como o termo a utilizar para identificar as múltiplas formas visíveis do gênero nãobinário; c) Adequação da linguagem no tratamento social das pessoas não-binárias como fundamental para a inclusão de pessoas não-binárias. Isso implica o questionamento individual sobre a forma como se dirigir socialmente às pessoas, como a aplicação do artigo [o/a] ou a aplicação de um pronome neutro.

${ }^{3}$ BRAZÃO, P. Apresentação do projeto vozes dos estudantes universitários sobre a diversidade sexual e de género, sua relação com a coeducação e com a inovação pedagógica: um estudo comparativo na Universidade da Madeira e na Universidade Federal de Sergipe. The Brain, 2021. Disponível em: https://bra.in/7vA6Q3. Acesso em: 10 jul. 2021.

${ }^{4}$ Espera-se com a pesquisa possa contribuir para a renovação conceitual e dos contextos organizacionais da prática da pedagogia (BRAZÃO; OLIVEIRA; DIAS, 2021; CARDOSO; DIAS, 2021; PALMEIRA; DIAS, 2021; CARDOSO et al., 2021; SANTOS; LAGE, 2017; SANTOS; RIOS, 2021; RIOS; VIEIRA, 2020; VIVAS, BASTIDAS 2020; SILVA; DIAS; RIOS, 2020; CARDOSO; DIAS, 2020; MENEZES; DIAS, 2020; CROCIARI; PEREZ, 2019; LUCIFORA et. al., 2019; CARDOSO; MELO, 2021; ALMEIDA; JAEHN; VASCONCELLOS, 2018; VILAÇA, 2019). 


\section{Metodologia da investigação}

A pesquisa apresenta uma abordagem metodológica qualitativa de natureza exploratória (NASCIMENTO; CAVALCANTE, 2018; NUNES, 2020; ALVES; FIALHO; LIMA, 2018; VILAÇA, 2019; ALMEIDA; JAEHN; VASCONCELLOS, 2018; FELICETTI, 2019; MEDEIROS; AGUIAR, 2018; ROCHA; MALHEIRO, 2019; SEVERINO, 2019; MAFRA; SÁ, 2020). Neste artigo iremos apenas apresentar o estudo comparativo das enunciações dos ex-estudantes acerca de gênero não-binário, nos dois contextos universitários: Universidade Federal de Sergipe (UFS) e Universidade da Madeira (UMa).

Os questionários que serviram ao levantamento dos dados desta categoria mantiveram o mesmo número de questões, tendo o texto sido adaptados com expressões linguísticas aos dois contextos estudados. Em primeiro, foi solicitado aos ex-estudantes que assistissem ao vídeo Canal das Bee. \#GuiaBasicoLGBT. - Gênero não-binário.

\section{Quadro 1 - Transcrição do conteúdo verbal do vídeo Gênero não-binário}

... Hoje a gente vai falar sobre o que é ser não-binário ou não-binária ... sempre importa a gente lembrar que há [inúmeras] possibilidades [de] ser um homem ... [ou de] ser mulher ... você pode ser os dois ou até mesmo nenhum dos dois ou seja existe muito mais coisas para além de [saber se deve ser] homem [ou se] deve ser mulher ....[as] pessoas que vão além do gênero que lhe foi designado ... as pessoas não-binárias precisaram de se colocar de forma a se sentirem mais apresentadas ... por isso surgiu o termo binário e não-binário ... [isto] é uma coisa muito importante ... as coisas mudam com o tempo ... quer dizer os hábitos e ... então vamos combinar e deixar a cabeça aberta ... e não começar a julgar um amiguinho que não se encaixa em alguma [categoria] ... senão a gente vai estar fazendo o mesmo [como o que aconteceu no passado] ... Queer é um termo usado [para] as pessoas não-binárias. Quem são essas pessoas que não se identificam necessariamente como homem ou como mulher? ... [Queer é] como se fosse um termo guarda-chuva ... Quando a gente está falando de gêneros não-binários a gente tem que pensar noutra coisa: separação entre gênero e expressão de gênero ... como a gente já falou aqui em um dos vídeos do canal ... [expressão de gênero] é como você se expressa ... existem pessoas não-binárias [que estão] exercendo uma separação do gênero ou mais masculina ou mais feminina ... algumas dessas pessoas sentem a necessidade de fazer intervenções cirúrgicas ou de fazer tratamentos hormonais ... mas não é só isso que caracteriza uma pessoa não-binária ... o importante é que a gente estar falando de uma pessoa ... [da complexidade] humana e não de uma lei ... uma coisa com a qual se pode legislar sobre ... e nem um juiz advogado médico ou qualquer outro profissional pode ter o direito de julgar o que você é e como você se identifica. Perguntaram-me se a pessoa não-binária não se sente confortável com o gênero ... como é que eu vou saber? como que eu vou tratar? ... já sabe a resposta ... tem de perguntar ... a forma mais fácil de acertar é perguntando para a pessoa como ela quer ser tratada ... e [depois] a gente deve tratar desse modo essa pessoa ... mais importante é que vocês prezam ... suponha que a pessoa quer ser chamada [de um modo] ou [de outro] essas coisas podem acabar machucando as pessoas ... por isso sempre pergunto ... por exemplo: como você deseja que eu trate você? ... qual pronome [que] eu posso usar com você? ... como é que você se chama? ... isso é uma base segura pois há situações em que as pessoas ficam com um pronome ... outras preferem o pronome neutro, como hoje é identificado quando a gente troca o / a ... sabe o que que é isso? ... é porque a língua portuguesa é muito complexa ... mas isso tem em todas as línguas? ... as pessoas vêm se adaptando é muito importante lembrar que a linguagem é mutável ... gente! a nossa língua portuguesa ... hoje a gente usa palavras e se comunica de uma maneira que não se comunicava há 15 anos atrás ... há 20 anos atrás e muito menos há 100 anos atrás ... porque é tudo uma questão de costume ... então como é que está começando a usar esse para homens e é saber se as regras é importante você saiba aqui tudo bem a sim contanto que seja sequer tempo para amanhã intenção tem que tentar fazer pá para não ofender as pessoas estão a sua bom isso está menos ... para fechar esse vídeo vou falar mais uma frase maravilhosa sobre ser não-binário tem verdades e autonomia de trazer a nossa existência para as nossas mãos ..

Fonte: Canal das Bee (2018)

RPGE- Revista on line de Política e Gestão Educacional, Araraquara, v. 25, n. 3, p. 2886-2909, set./dez. 2021. e-ISSN: 1519-9029 
Em segundo, foram apresentadas duas questões de resposta fechada, uma de resposta boleana ( $\operatorname{sim} /$ não) sobre o conhecimento do conceito de género não-binário e uma outra de resposta em escala Likert, de 5 níveis, indagando a frequência com que em contexto acadêmico participaram em conversas, debates sobre este conceito. Finalmente uma questão de resposta aberta, tentando obter a opinião sobre este tema. Os questionários encontram-se acessíveis nos links abaixo especificados ${ }^{5}$.

Para recolha de informação foi utilizado o Google Forms, da Google Drive resources. Definimos dois grupos de amostra de conveniência: a) os ex-estudantes do curso de mestrado em Educação Pré-Escolar e Ensino do $1^{\circ}$ Ciclo do Ensino Básico, da UMa, entre 2015 e 2020; b) os ex-estudantes do curso de graduação em Pedagogia, da UFS, entre 2015 e 2020.

Os dados qualitativos foram analisados com o auxílio de um programa informático que elaborado para executar a análise de conteúdo (BARDIN, 1997) e que inclui a transcrição das justificações dos egressos, a construção das categorias de análise, em tabelas, ilustradas pelas unidades de significação semântica (BOGDAN; BLIKEN, 2017). Os recortes textuais foram codificados com a seguinte lógica: [País (PT ou Br) (-); campus universitário Itabaiana (ITA) ou São Cristóvão (SC); número de anos em que encontram após conclusão do curso (1...); número de ordem de resposta $(1 \ldots)]$.

Foi utilizada a ferramenta FileMaker Pro v18, elaboradora de bases de dados relacionais, da Claris International Inc, desenvolvido para o Windows. Para além de organizar os recortes categorizados e subcategorizados dos textos, o programa contém conexões com um módulo de interpretação dos dados, uma vez que estabelece uma relação direta entre a análise dos recortes obtidos e os referenciais teóricos, selecionados para fundamentar a interpretação dos fenómenos, conforme Figura 1.

5 Para os ex-estudantes da Universidade da Madeira. Disponível em: https://drive.google.com/file/d/1okl9ue088QFOy2dBtuyvQ9xXSTLmvKi/view?usp=sharing. Acesso em: 10 out. 2021.

Para os ex-estudantes da Universidade Federal de Sergipe. Disponível em: https://drive.google.com/file/d/14M7EWnjiB3-yQWtFUD-0JbJKmX1YU-0Y/view?usp=sharing. Acesso em: 10 out. 2021 . 
Figura 1 - Base de dados para análise de conteúdo dos dados qualitativos

Fonte: Os autores (2021)

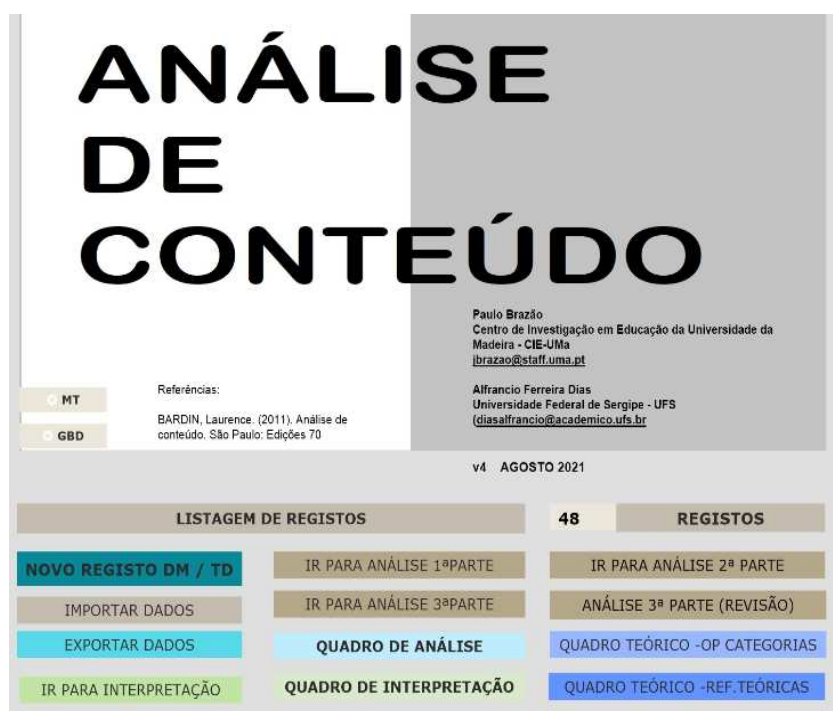

Os textos com as afirmações dos ex-estudantes foram arrumados por unidades de significação semântica, conforme sugerem Bardin (1997) e Bogdan e Bliken (2017). A categoria de gênero, analisada neste artigo deu origem a subcategorias e cada uma delas foi justificada com diferentes fenômenos, conforme apresentamos no quadro 1 sobre a categorização dos resultados.

Quadro 2 - Categorização dos discursos dos ex-estudantes

\begin{tabular}{|c|l|}
\hline \multicolumn{2}{|c|}{ Categoria: GÊNERO } \\
\hline Subcategoria & \multicolumn{1}{|c|}{ Fenômenos } \\
\hline GÊNERO NÃO-BINÁRIO (+) & Valorização do conceito de gênero não-binário. \\
\hline GÊNERO NÃO-BINÁRIO (-) & $\begin{array}{l}\text { Valorização da não binariedade, centrada na } \\
\text { construção/reconstrução subjetiva da identidade. }\end{array}$ \\
\hline GÊNERO NÃO-BINÁRIO (N) & $\begin{array}{l}\text { Constrangimentos na vivência da não binariedade } \\
\text { motivada pela influência de padrões sociais } \\
\text { estereotipados. }\end{array}$ \\
\hline Não valorização do conceito de gênero não-binário. \\
\hline
\end{tabular}

Fonte: Os autores (2021)

Considerou-se que "Gênero" seria a categoria principal que inclui o gênero nãobinário. Analisando as respostas dos participantes obteve-se três subcategorias: a primeira subcategoria "Gênero não-binário (+)" aglomerou os fenêmenos: valorização do conceito de RPGE- Revista on line de Política e Gestão Educacional, Araraquara, v. 25, n. 3, p. 2886-2909, set./dez. 2021. e-ISSN: 1519-9029 DOI: https://doi.org/10.22633/rpge.v25i3.15680 
gênero não-binário; valorização da não binariedade, centrada na construção/reconstrução subjetiva da identidade. A segunda subcategoria, designada de "Gênero não-binário (-)" reuniu os fenêmenos considerados não positivos tais como: constrangimentos na vivência da não binariedade motivada pela influência de padrões sociais estereotipados; não valorização do conceito de gênero não-binário. A terceira subcategoria "Gênero não-binário $(\mathrm{N})$ " refere-se ao desconhecimento do conceito de gênero não-binário.

\section{Caracterização dos sujeitos}

Foi solicitado o preenchimento do questionário a 160 ex-estudantes da Universidade da Madeira. Destes apenas obtivemos 22 respostas (13,7\%). De igual modo enviámos a 183 ex-estudantes da Universidade Federal de Sergipe e obtivemos 26 respostas (14,21\%).

Quanto ao gênero, no grupo dos ex-estudantes da Universidade da Madeira (UMa), $95,5 \%$ identifica-se como mulher e 4,5\% como homem. No grupo dos ex-estudantes da Universidade Federal de Sergipe (UFS), 76,9\% identifica-se como mulher e 23,1\% como homem.

Relativamente ao tempo decorrido após a conclusão do curso de formação na Universidade da Madeira (UMa) e na Universidade Federal de Sergipe (UFS), verificamos ainda o seguinte: a) Na Universidade da Madeira (UMa), a maior percentagem de participantes (33\%) diz respeito a ex-estudantes que concluíram o curso há um ano ou menos, $29 \%$ de ex-estudantes concluiu o curso há três anos e $24 \%$ concluiu o curso há cinco anos; b) Na Universidade Federal de Sergipe (UFS), a maior percentagem (46\%) é composta por exestudantes que concluíram o curso há cinco ou mais anos, $23 \%$ de ex-estudantes concluíram concluiu o curso há três anos e 19\% concluiu o curso há quatro anos, conforme a Figura 2. 
Figura 2 - Tempo decorrido após a conclusão do curso de formação na Universidade da Madeira (UMa) e na Universidade Federal de Sergipe (UFS)

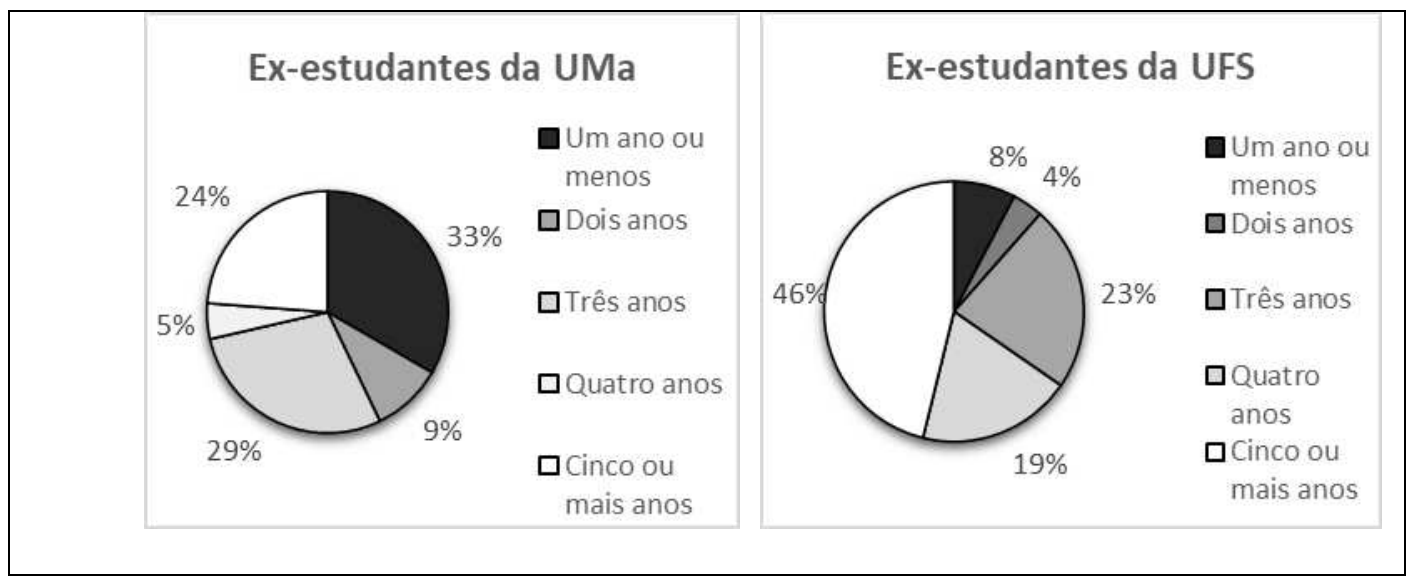

Fonte: Os autores (2021)

Comparando os grupos de ex-estudantes, relativamente ao tempo decorrido após a conclusão dos cursos de formação inicial de professores, vemos que o grupo de ex-estudantes da UMa concluiu a sua formação mais recentemente que os seus pares no curso de Pedagogia, na UFS.

\section{Análise do discurso verbal do vídeo}

Procedemos a uma análise do discurso do vídeo utilizado para o enquadramento da subcategoria de gênero não-binário, conforme Quadro 3.

Quadro 3 - Análise do discurso verbal do vídeo "Género não binário" Subcategoria: GÊNERO NÃO-BINÁRIO

Conteúdo semântico Considerações

... Hoje a gente vai falar sobre o que é ser não-binário ou Identificação do tema de gênero não-binário. não-binária

... sempre importa a gente lembrar que há [inúmeras] Apresentação do conceito de gênero não-binário possibilidades [de] ser um homem ... [ou de] ser mulher ... como a variação dos modos de vivenciar o você pode ser os dois ou até mesmo nenhum dos dois ou seja, gênero, para além da polarização homem/mulher. existe muito mais coisas para além de [saber se deve ser] homem [ou se] deve ser mulher ... [as] pessoas que vão além do género que lhe foi designado .... as pessoas não-binárias precisaram de se colocar de forma a se sentirem mais apresentadas ... por isso surgiu o termo binário e não-binário ... [isto] é uma coisa muito importante...as coisas mudam com o tempo ... quer dizer os hábitos e ... então vamos combinar e deixar a cabeça aberta ... e não começar a julgar um amiguinho que não se encaixa em alguma [categoria] ... senão a gente vai estar fazendo o mesmo [como o que aconteceu no passado] 
... Queer é um termo usado [para] as pessoas não-binárias. Apresentação do termo Queer como adequado à Quem são essas pessoas que não se identificam identificação do conceito de gênero não binário. necessariamente como homem ou como mulher? ... [Queer é] como se fosse um termo guarda-chuva

... Quando a gente está falando de gêneros não-binários a Apresentação do termo expressão de gênero para gente tem que pensar noutra coisa: separação entre género e identificar as múltiplas formas visíveis do gênero expressão de gênero ... como a gente já falou aqui em um não-binário.

dos vídeos do canal ... [expressão de gênero] é como você se expressa ... existem pessoas não binárias [que estão] exercendo uma separação do gênero ou mais masculina ou mais feminina ... algumas essas pessoas sentem a necessidade de fazer intervenções cirúrgicas ou de fazer tratamentos hormonais ... mas não é só isso que caracteriza uma pessoa não-binária ... o importante é que a gente estar falando de uma pessoa ... [da complexidade] humana e não de uma lei ... uma coisa com a qual se pode legislar sobre ... e nem um juiz advogado médico ou qualquer outro profissional pode ter o direito de julgar o que você é e como você se identifica.

Perguntaram-me se a pessoa não binária não se sente Apelo ao tratamento social das pessoas nãoconfortável com o gênero ... como é que eu vou saber? como binárias, que implica necessariamente o que eu vou tratar? ... já sabe a resposta ... tem de perguntar questionamento individual sobre a linguagem a ... a forma mais fácil de acertar é perguntando para a pessoa adequar quando se dirigir socialmente à pessoa, como ela quer ser tratada ... e [depois] a gente deve tratar como por exemplo:

desse modo essa pessoa ... mais importante é que vocês - a aplicação do artigo [o/a]

prezam ... suponha que a pessoa quer ser chamada [de um - a aplicação de um pronome neutro

modo] ou [de outro] essas coisas podem acabar machucando

as pessoas ... por isso sempre pergunto ... por exemplo: como você deseja que eu trate você? ... qual pronome [que] eu posso usar com você? ... como é que você se chama? ... isso é uma base segura pois há situações em que as pessoas ficam com um pronome ... outras preferem o pronome neutro, como hoje é identificado quando a gente troca [o/a] ... sabe o que que é isso? ... é porque a língua portuguesa é muito complexa ... mas isso tem em todas as línguas? ... as pessoas vêm se adaptando é muito importante lembrar que a linguagem é mutável ... gente! a nossa língua portuguesa ... hoje a gente usa palavras e se comunica de uma maneira que não se comunicava há 15 anos atrás ... há 20 anos atrás e muito menos há 100 anos atrás ... porque é tudo uma questão de costume ... então como é que está começando a usar esse para homens e é saber se as regras é importante você saiba aqui tudo bem a sim contanto que seja sequer tempo para amanhã intenção tem que tentar fazer pá para não ofender as pessoas estão a sua bom isso está menos ... para fechar esse vídeo vou falar mais uma frase maravilhosa sobre ser nãobinário tem verdades e autonomia de trazer a nossa existência para as nossas mãos ...

Fonte: Os autores (2021)

Embora a transcrição do texto apresente muitas marcas de oralidade, foi possível sistematizar o seguinte: a) $\mathrm{O}$ conceito de gênero não-binário é descrito como a variação dos modos de vivenciar o gênero, para além da polarização homem/mulher; b) O termo Queer é apresentado como o adequado à identificação do conceito de gênero não-binário; c) $\mathrm{O}$ termo expressão de gênero é apresentado para identificar as múltiplas formas visíveis do gênero não- 
binário; d) É necessário cuidar da adequação da linguagem no tratamento social das pessoas não-binárias. Isso implica o questionamento individual sobre a forma como se dirigir à pessoa, a saber: a aplicação do artigo [o/a] ou a aplicação de um pronome neutro. Estas informações breves situaram os participantes sobre o conhecimento ou reconhecimento do conceito de gênero não-binário, no momento em que foram solicitados a preencher o questionário.

\section{Discussão dos resultados}

Relativamente ao conhecimento do conceito de gênero não-binário, as respostas dos ex-estudantes de ambas as universidades estão globalmente muito próximas, embora com um resultado superior nos participantes na UMa. 86,4\% de ex-estudantes diz que conhece o conceito de gênero não-binário e na UFS, 73,1\% também afirma o mesmo. Correspondentemente, $13,6 \%$ dos ex-estudantes da UMa, e 26,9\% dos ex-estudantes da UFS respondem não ter conhecimento deste, conforme se verifica na Figura 3.

Figura 3 - Conhecimento dos ex-estudantes sobre o conceito de gênero não-binário

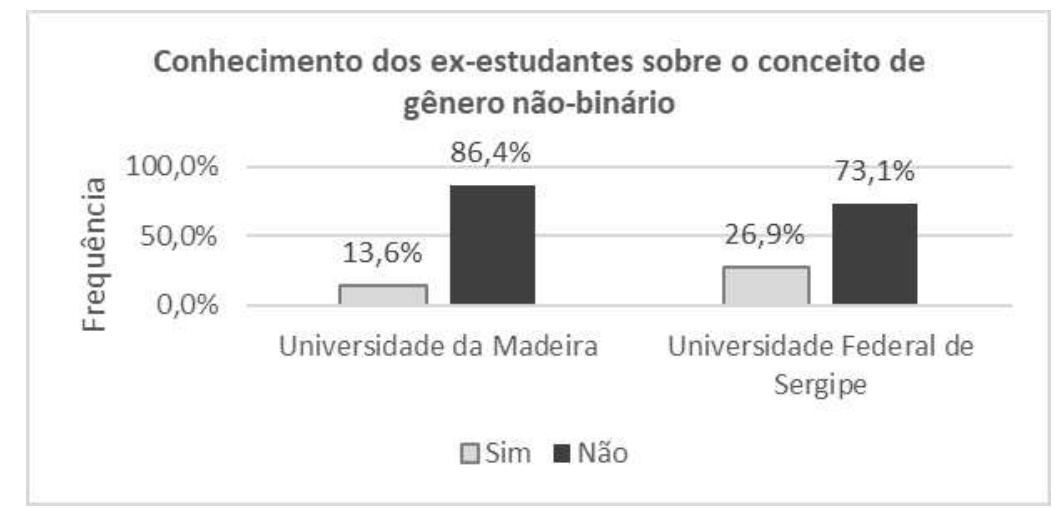

Fonte: Os autores (2021)

As respostas dos ex-estudantes na Universidade da Madeira confirmam pouca participação. A grande percentagem (90,9\%) de ex-estudantes na Universidade da Madeira nunca participou em conversas e debates sobre gênero não-binário. Existe uma pequena percentagem $(9,1 \%)$ de ex-estudantes da UMa a afirmar que raramente participou em ações sobre este tema, conforme se verifica na Figura 4.

As respostas dos ex-estudantes na Universidade Federal de Sergipe confirmam igualmente pouca participação embora com menor percentagem $(65,4 \%)$ de ex-estudantes nunca participou em conversas e debates sobre gênero não-binário. Existem 19\% de respostas 
dos ex-estudantes afirmando sempre participaram, $(7,7 \%)$ de participantes afirmam que raramente participam em ações sobre este tema e 3,8\% responde que participa às vezes.

Figura 4 - Participação dos ex-estudantes da UMa e da UFS em conversas e debates sobre gênero não-binário

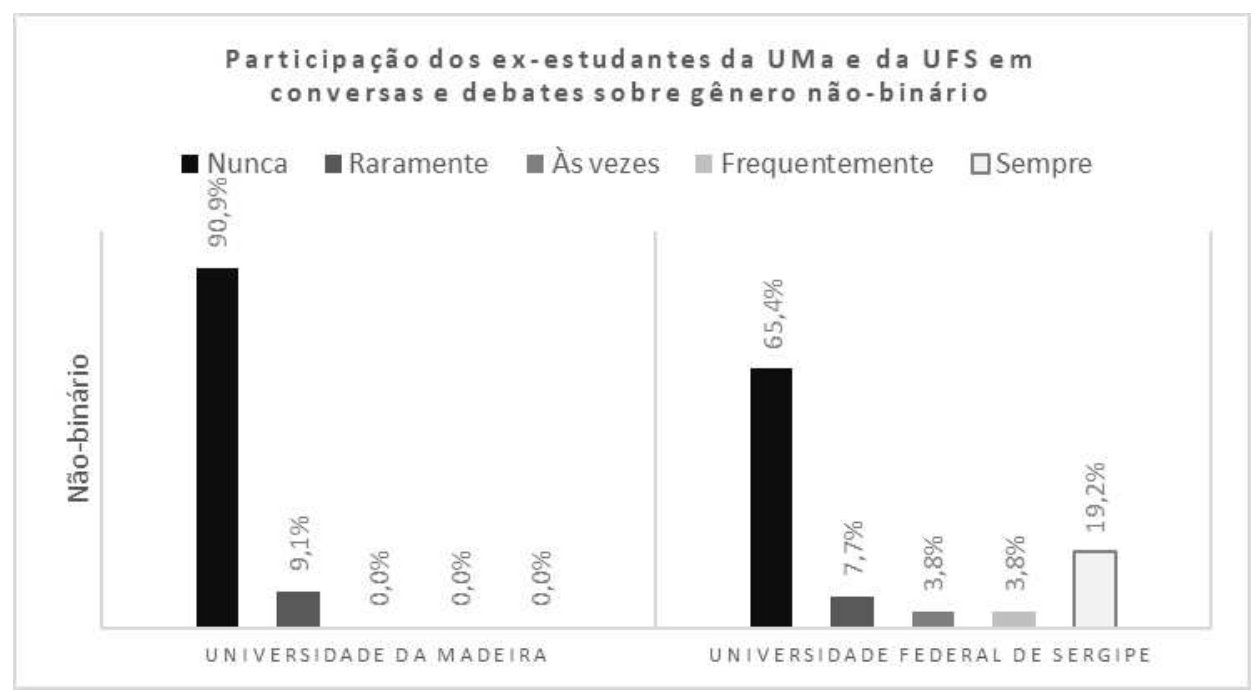

Fonte: Os autores (2021)

Comparando os resultados dos dois grupos, verifica-se que ambos confirmam pouco envolvimento em conversas e debates sobre gênero não-binário, sendo o grupo dos exestudantes da Universidade da Madeira o que diz participar menos. No grupo de ex-estudantes da Universidade Federal de Sergipe 19,2\% que disse sempre participou em conversas e debates sobre gênero não-binário.

$\mathrm{Na}$ análise de conteúdo às afirmações dos ex-estudantes, sobre a valorização do conceito de gênero não-binário, considerou-se as seguintes respostas dos participantes da UMa: "Muito interessante" (PT-1-02); "Devemos questionar como as pessoas devem ser tratadas." (PT-1-05); "Muito pertinente" (PT-5-21);

Na UFS, os ex-estudantes disseram: “É um tema importante (BR-ITA-3-02); "Não basta somente dizer que aceita algo, mas é preciso também se informar." (BR-ITA-3-03); "Bem esclarecido, complementando alguns conteúdos já vistos, (mararavilhose)." (BR-ITA-305); “É de grande relevância para entendemos como as pessoas querem ser tratadas, por isso é fundamental perguntar." (BR-ITA-4-08); "Interessante a forma da linguagem, para a conversa com o não-binário.” (BR-ITA-4-09); “É importante respeitar o próximo como ele é, e como ele gostaria de ser chamado, pois o sexo não define a sua real identidade, muito menos o seu conhecimento." (BR-ITA-5-13); "É importante respeitar o próximo como ele é, e como ele gostaria de ser chamado, pois o sexo não define a sua real identidade, muito menos o seu 
conhecimento." (BR-ITA-5-13); “Tema importante para compreender e respeitar a escolha do outro." (BR-ITA-5-14); "Muito bom (BR-ITA-5-15); "Importante e precisa ser debatido." (BR-SC-1-01); "Interessante" (BR-SC-5-04); "relevante" (BR-SC-5-05); "Muito importante" (BR-SC-5-07); "Relevante" (BR-SC-5-08); "O gênero não-binário é aquele que não se identifica com nenhum dos gêneros (masculino ou feminino), e que independente do sexo, classe social devemos respeitar e tratar da maneira como ele se vê e gostaria." (BR-ITA-512).

As expressões utilizadas pelos participantes confirmam o cuidado destes na adequação e no tratamento social para com as pessoas não-binárias. A palavra comum mais utilizada é respeito. Os ex-estudantes das duas universidades utilizam expressões semelhantes, embora os participantes da UFS sejam mais efusivos, conforme se observa no Quadro 4. 
Quadro 4 - Análise comparativa dos discursos dos ex-estudantes sobre a subcategoria de gênero não-binário $(+)$

\begin{tabular}{|c|c|c|}
\hline \multicolumn{3}{|c|}{ Categoria: GêNERO Subcategoria: GêNERO NÃO-BINÁRIO (+) } \\
\hline Fenômeno(s): & Ex-estudantes da UMa & Ex-estudantes da UFS \\
\hline $\begin{array}{l}\text { Valorização do } \\
\text { conceito de gênero não- } \\
\text { binário. }\end{array}$ & $\begin{array}{l}\text { Muito interessante (PT-1-02) } \\
\text { Devemos questionar como as } \\
\text { pessoas devem ser tratadas. (PT-1- } \\
\text { 05) } \\
\text { Muito pertinente (PT-5-21) } \\
\text { Respeito (PT-5-17) } \\
\text { Relevante na atualidade (PT-5-18) }\end{array}$ & $\begin{array}{l}\text { É um tema importante (BR-ITA-3-02) } \\
\text { Não basta somente dizer que aceita algo, mas é } \\
\text { preciso também se informar (BR-ITA-3-03) } \\
\text { Bem esclarecido, complementando alguns } \\
\text { conteúdos já vistos, (mararavilhose) (BR-ITA-3- } \\
\text { 05) } \\
\text { É de grande relevância para entendemos como as } \\
\text { pessoas querem ser tratadas, por isso é } \\
\text { fundamental perguntar. (BR-ITA-4-08) } \\
\text { Interessante a forma da linguagem, para a } \\
\text { conversa com o não binário. (BR-ITA-4-09) } \\
\text { O gênero não-binário é aquele que não si } \\
\text { identifica com nenhum dos gêneros (masculino } \\
\text { ou feminino), e que independente do sexo, classe } \\
\text { social devemos respeitar e tratar da maneira } \\
\text { como ele si vê e gostaria. (BR-ITA-5-12) } \\
\text { É importante respeitar o próximo como ele é, e } \\
\text { como ele gostaria de ser chamado, pois o sexo } \\
\text { não define a sua real identidade, muito menos o } \\
\text { seu conhecimento. (BR-ITA-5-13) } \\
\text { Tema importante para compreender e respeitar a } \\
\text { escolha do outro. (BR-ITA-5-14) } \\
\text { Muito bom (BR-ITA-5-15) } \\
\text { Importante e precisa ser debatido (BR-SC-1-01) } \\
\text { Interessante (BR-SC-5-04) } \\
\text { relevante (BR-SC-5-05) } \\
\text { Muito importante (BR-SC-5-07) } \\
\text { Relevante (BR-SC-5-08) } \\
\text { as pessoas precisam de estar atualizadas sobre. } \\
\text { (BR-ITA-3-02) }\end{array}$ \\
\hline $\begin{array}{l}\text { Valorização da não } \\
\text { binariedade, centrada } \\
\text { na construção/ } \\
\text { reconstrução subjetiva } \\
\text { da identidade. }\end{array}$ & $\begin{array}{l}\text { O mais importante é que cada um se } \\
\text { sinta bem. (PT-1-04) } \\
\text { As pessoas devem ser tratadas como } \\
\text { se sentem melhor (PT-1-07) } \\
\text { As pessoas não devem ser julgadas, } \\
\text { mas sim respeitadas e integradas. } \\
\text { (PT-2-08) pessoas não são } \\
\text { Estas nas existe } \\
\text { compreendidas porque não } \\
\text { muita informação sobre este tema. } \\
\text { (PT-3-12) } \\
\text { As pessoas devem ser respeitadas } \\
\text { (PT-5-20) }\end{array}$ & $\begin{array}{l}\text { sempre lembrar como as pessoas querem ser } \\
\text { tratadas. (BR-ITA-3-05) } \\
\text { Que devemos respeitar o próximo e perguntar } \\
\text { como que ser tratado (BR-ITA-3-06). } \\
\text { E também para saber como tratar e se referir uma } \\
\text { pessoa de gênero não-binário perguntando qual a } \\
\text { melhor forma de tratá-la em relação ao gênero } \\
\text { que se identifica. (BR-ITA-5-14) }\end{array}$ \\
\hline
\end{tabular}

Fonte: Os autores (2021) 
Sobre a valorização da não binariedade, centrada na construção/reconstrução subjetiva da identidade, encontram-se as afirmações dos ex-estudantes da UMa: “As pessoas deveriam ser respeitadas pelos outros (PT-1-03); “O mais importante é que cada um se sinta bem.” (PT1-04); "As pessoas devem ser tratadas como se sentem melhor." (PT-1-07). Os ex-estudantes da UFS disseram: "sempre lembrar como as pessoas querem ser tratadas." (BR-ITA-3-05); "Que devemos respeitar o próximo e perguntar como que ser tratado.” (BR-ITA-3-06); “...e também para saber como tratar e se referir uma pessoa de gênero não-binário perguntando qual a melhor forma de tratá-la em relação ao gênero que se identifica.” (BR-ITA-5-14).

Sobre os constrangimentos relativos à vivência do gênero não-binário, são os exestudantes da UFS que manifestam estranhamento perante a complexidade do tema e mencionam o seguinte: "Por que quando se fala em ser aceito parece que são pessoas de outro mundo e não são, somos todos/as pessoas e como tudo com gostos, vivencias, vidas e amores diferentes. Vemos que ninguém quer ser igual ao outro mas grande parte quer exigir que sejam cisgeneros e héteros.” (BR-ITA-4-11); "É um questionamento pouco divulgado, muitos não tem o conhecimento de causa, com isso fica mais complicado entender.” (BR-SC-5-03); "estar por dentro das coisas pra não acabar "sem querer" julgando ou cometendo um ato de preconceito com alguém.” (BR-ITA-3-03); “Entendo que as pessoas podem ser uma coisa ou outra coisa, ou as duas coisas, mas pessoas que é uma coisa, nem outra, ainda é uma incógnita. Pra mim tenho pouca informação sobre o assunto." (BR-ITA-3-04); "Porém respeito, lutem e mudem pelo que acreditam e acham que tem importância. O português já é complexo e ainda mudar vogais porque a pessoa não se identifica, respeito as pessoas, seu gênero e a sexualidade de cada um mas isso não acho necessário, os/as LGBTQI+ tem muita luta para as pessoas os/as respeitarem. Por que quando se fala em ser aceito parece que são pessoas de outro mundo e não são, somos todos/as pessoas e como tudo com gostos, vivencias, vidas e amores diferentes. Vemos que ninguém quer ser igual ao outro mas grande parte quer exigir que sejam cisgeneros e héteros" (BR-ITA-4-11); "É um questionamento pouco divulgado, muitos não tem o conhecimento de causa, com isso fica mais complicado entender" (BR-SC-5-03).

Verifica-se uma forte consciência da maioria dos ex-estudantes da UFS para os constrangimentos na vivência da não binariedade, motivada pela influência de padrões sociais estereotipados. Isso é justificado na referência de contextos sociais com tabus sobre esta temática e que dificultam a livre vivência do gênero.

$\mathrm{Na}$ análise comparativa dos discursos observa-se que tanto os ex-estudantes da UMa como os da UFS valorizam o conceito de gênero não-binário e reconhecem a necessidade de 
discuti-lo. Utilizam também expressões idênticas quando fazem considerações valorativas sobre este conceito. No entanto verifica-se uma forte consciência da maioria dos exestudantes da UFS relativamente aos constrangimentos na vivência do gênero não-binário. São os ex-estudantes da UFS que mais referem que os constrangimentos são causados pela influência de padrões sociais estereotipados.

Quadro 5 - Análise comparativa dos discursos dos ex-estudantes sobre a subcategoria de gênero não-binário (-)

\begin{tabular}{|c|c|c|}
\hline \multicolumn{3}{|c|}{ Categoria: GÊNERO Subcategoria: GÊNERO NÃO-BINÁRIO (-) } \\
\hline Fenômeno(s): & Ex-estudantes da UMa & Ex-estudantes da UFS \\
\hline $\begin{array}{l}\text { Constrangimentos na } \\
\text { vivência da não } \\
\text { binariedade motivada } \\
\text { pela influência de } \\
\text { padrões sociais } \\
\text { estereotipados. }\end{array}$ & $\begin{array}{l}\text { As pessoas deveriam ser respeitadas } \\
\text { pelos outros (PT-1-03) }\end{array}$ & $\begin{array}{l}\text { Estar por dentro das coisas pra não acabar } \\
\text { "sem querer" julgando ou cometendo um ato } \\
\text { de preconceito com alguém. (BR-ITA-3-03) } \\
\text { Entendo que as pessoas podem ser uma coisa } \\
\text { ou outra coisa, ou as duas coisas, mas pessoas } \\
\text { que é uma coisa, nem outra, ainda é uma } \\
\text { incógnita. Pra mim tenho pouca informação } \\
\text { sobre o assunto. (BR-ITA-3-04) } \\
\text { Porém respeito, lutem e mudem pelo que } \\
\text { acreditam e acham que tem importância. O } \\
\text { português já é complexo e ainda mudar vogais } \\
\text { porque a pessoa não se identifica, respeito as } \\
\text { pessoas, seu gênero e a sexualidade de cada } \\
\text { um mas isso não acho necessário, os/as } \\
\text { LGBTQI+ tem muita luta para as pessoas os/as } \\
\text { respeitarem. Por que quando se fala em ser } \\
\text { aceito parece que são pessoas de outro mundo } \\
\text { e não são, somos todos/as pessoas e como tudo } \\
\text { com gostos, vivencias, vidas e amores } \\
\text { diferentes. Vemos que ninguém quer ser igual } \\
\text { ao outro mas grande parte quer exigir que } \\
\text { sejam cisgeneros e héteros. (BR-ITA-4-11) } \\
\text { É um questionamento pouco divulgado, muitos } \\
\text { não tem o conhecimento de causa, com isso } \\
\text { fica mais complicado entender. (BR-SC-5-03) }\end{array}$ \\
\hline $\begin{array}{l}\text { Não valorização do } \\
\text { conceito de gênero não- } \\
\text { binário. }\end{array}$ & $\begin{array}{l}\text { confuso (PT-3-15) } \\
\text { Acho que quanto mais conceitos } \\
\text { criam, mais confuso se torna de } \\
\text { compreender. Porque simplesmente } \\
\text { cada um não pode ser como é, sem } \\
\text { ter que se encaixar num determinado } \\
\text { conceito? (PT-2-09) }\end{array}$ & $\begin{array}{l}\text { Acredito que Deus criou homem e mulher. } \\
\text { (BR-SC-5-06) } \\
\text { Um pouco desconexo. (BR-ITA-3-04) } \\
\text { É um tema um pouco complexo. (BR-ITA-2- } \\
\text { 01) } \\
\text { Eu não acho isso muito relevante não, não sei } \\
\text { se porque não é comigo não tenho essa } \\
\text { necessidade. (BR-ITA-4-11) } \\
\text { Confuso (BR-SC-5-09) }\end{array}$ \\
\hline
\end{tabular}

Fonte: Os autores (2021)

A não valorização deste conceito, embora com menos ênfase, está expressa em afirmações dos ex-estudantes das duas universidades. As justificações são muito semelhantes: 
“confuso" (PT-3-15); "Um pouco desconexo." (BR-ITA-3-04); "É um tema um pouco complexo.” (BR-ITA-2-01); Eu não acho isso muito relevante não, não sei se porque não é comigo não tenho essa necessidade.” (BR-ITA-4-11); “Confuso” (BR-SC-5-09. "Acho que quanto mais conceitos criam, mais confuso se torna de compreender. Porque simplesmente cada um não pode ser como é, sem ter que se encaixar num determinado conceito?” (PT-209). É possível que o questionamento continuado tenha originado alguma fadiga entre os participantes. No entanto estão presentes a expressões de estranhamento face ao conceito de gênero não-binário. $\mathrm{O}$ estranhamento assume uma posição radical na voz desta participante: "Acredito que Deus criou homem e mulher." (BR-SC-5-06). A participante muda o tema para mostrar total indisponibilidade para continuar a discutir este conceito.

Quadro 6 - Análise comparativa dos discursos dos ex-estudantes sobre a subcategoria de gênero não-binário $(\mathrm{N})$

\begin{tabular}{|c|c|c|}
\hline \multicolumn{3}{|c|}{ Categoria: GÊNERO Subcategoria: GÊNERO NÃO-BINÁRIO (N) } \\
\hline Fenômeno(s): & Ex-estudantes da UMa & Ex-estudantes da UFS \\
\hline $\begin{array}{l}\text { Desconhecimento do } \\
\text { conceito de gênero não- } \\
\text { binário. }\end{array}$ & $\begin{array}{l}\text { Este tema está a se revelar mais } \\
\text { profundo do que eu conhecia. } \\
\text { Desconhecia por completo o termo } \\
\text { utilizado. (PT-3-11) Desconhecia } \\
\text { este termo. (PT-3-13) } \\
\text { Não sabia. São muitos conceitos e } \\
\text { dificulta a compreensão. (PT-3-14) } \\
\text { Parece estranho (PT-5-19) } \\
\text { Não conhecia este tema (PT-5-22) } \\
\text { Este conceito não é muito conhecido. } \\
\text { (PT-3-10) } \\
\text { O Conceito de género não-binário } \\
\text { não é muito conhecido. (PT-3-12) } \\
\text { Termo desconhecido, porém de fácil } \\
\text { compreensão, aquando do } \\
\text { esclarecimento. (PT-1-01) } \\
\text { Um tema que não me faz quaisquer } \\
\text { confusão. (PT-1-04) }\end{array}$ & $\begin{array}{l}\text { Não tenho opinião ainda formada, mas saiba } \\
\text { que têm o meu respeito (BR-ITA-3-07) } \\
\text { Precisamos ter mais conhecimento sobre ele, } \\
\text { pois é algo que não ouvimos com frequência } \\
\text { sobre o mesmo, e assim não chegar ao ponto } \\
\text { de ofender por falta entendimento. (BR-ITA- } \\
\text { 4-10) } \\
\text { Não conhecia muito sobre esse gênero. (BR- } \\
\text { ITA-5-16) } \\
\text { Nenhum [conhecimento] (BR-ITA-5-17) É } \\
\text { um questionamento pouco divulgado, muitos } \\
\text { não tem o conhecimento de causa, com isso } \\
\text { fica mais complicado entender. (BR-SC-5- } \\
\text { 03) }\end{array}$ \\
\hline
\end{tabular}

Fonte: Os autores (2021)

Sobre o desconhecimento do conceito de pessoa não-binária, são os participantes da UMa os que mais afirmam: "Desconhecia este termo." (PT-3-13); "Não sabia. São muitos conceitos e dificulta a compreensão." (PT-3-14); "Parece estranho" (PT-5-19); "Não conhecia este tema" (PT-5-22); "Este conceito não é muito conhecido." (PT-3-10); "O Conceito de género não-binário não é muito conhecido.” (PT-3-12); “Termo desconhecido, porém de fácil compreensão, aquando do esclarecimento." (PT-1-01).

Os participantes da UFS, em menor número, também dizem desconhecer o conceito: "Não tenho opinião ainda formada, mas saiba que têm o meu respeito." (BR-ITA-3-07); 
"Precisamos ter mais conhecimento sobre ele, pois é algo que não ouvimos com frequência sobre o mesmo, e assim não chegar ao ponto de ofender por falta entendimento." (BR-ITA-410); "Não conhecia muito sobre esse gênero." (BR-ITA-5-16); “É um questionamento pouco divulgado, muitos não tem o conhecimento de causa, com isso fica mais complicado entender" (BR-SC-5-03).

Estes dados dão conta da necessidade de ações informativas no campo da educação e no meio acadêmico para que o conceito de gênero, nas suas mais variadas expressões ganhe outra familiaridade.

\section{Considerações finais}

Os ex-estudantes de ambas as universidades revelam conhecer o conceito de gênero não-binário. As respostas estão globalmente muito próximas, embora com um resultado superior nos participantes na UMa.

As respostas dos ex-estudantes na Universidade da Madeira confirmam pouca participação em conversas e debates sobre este tema. A grande maioria nunca participou em conversas e debates sobre gênero não-binário. Existe uma pequena percentagem de exestudantes da UMa a afirmar que raramente participou em ações sobre este tema.

As respostas dos ex-estudantes na Universidade Federal de Sergipe confirmam igualmente pouca participação embora com menor percentagem de respostas. Destacamos ainda um pequeno grupo de ex-estudantes que afirmou que sempre participou.

Comparando os resultados dos dois grupos, verifica-se que ambos confirmam pouco envolvimento em conversas e debates sobre gênero não-binário, sendo o grupo dos exestudantes da Universidade da Madeira o que diz participar menos. Existe um grupo de exestudantes da Universidade Federal de Sergipe que afirmou que sempre participou em conversas e debates sobre gênero não-binário.

As respostas são semelhantes nos ex-estudantes das duas universidades, embora mais efusivas nos participantes da UFS. Sobre os constrangimentos relativos à vivência do gênero não-binário, são os ex-estudantes da UFS que referem que aqueles são causados pelos padrões sociais estereotipados.

Verifica-se uma forte consciência da maioria dos ex-estudantes da UFS para os constrangimentos na vivência da não binariedade, motivada pela influência de padrões sociais estereotipados. 
$\mathrm{Na}$ análise comparativa dos discursos observa-se que tanto os ex-estudantes da UMa como os da UFS valorizam o conceito de gênero não-binário e reconhecem a necessidade de discuti-lo. Utilizam também expressões idênticas quando fazem considerações valorativas sobre este conceito. No entanto verifica-se uma forte consciência da maioria dos exestudantes da UFS relativamente aos constrangimentos na vivência do gênero não-binário. São os ex-estudantes da UFS que mais referem que os constrangimentos são causados pela influência de padrões sociais estereotipados.

São os participantes da UMa os que mais afirmam desconhecer o conceito de gênero não-binário. Alguns participantes da UFS, em menor número, também dizem desconhecer o conceito.

Verifica-se também com menos ênfase, fenómenos de não valorização do conceito de gênero não-binário. Uma participante mostrou total indisponibilidade para continuar a discutir este conceito.

Uma vez que os participantes das duas universidades valorizam o conceito de gênero não-binário deduz-se que são favoráveis à subversão do gênero, como aspeto considerado legítimo e importante para a afirmação dos sujeitos na produção de corpos performativamente inteligíveis e críticos. No entanto, os participantes não se manifestaram sobre o tratamento social das pessoas não-binárias como fundamental para a inclusão destas. Este cuidado operativo da inclusão da diversidade sexual e de gênero implica a adequação da linguagem e o questionamento individual sobre a forma como se dirigir socialmente às pessoas não-binárias.

Conclui-se que há necessidade de ações informativas no campo da educação e no meio acadêmico para que o conceito de gênero não-binário ganhe plena familiaridade e conhecimento.

AGRADECIMENTOS: Ao CNPq pelo financiamento da pesquisa na modalidade de bolsa.

\section{REFERÊNCIAS}

ALMEIDA, S. M.; JAEHN, L.; VASCONCELLOS, M. Precisamos falar de gênero: por uma educação democrática. Revista Ibero-Americana de Estudos em Educação, Araraquara, v. 13 , n. esp. 2, p. 1503-1517, 2018. DOI:

https://doi.org/10.21723/riaee.v13.nesp2.set2018.11657

ALMEIDA, W. R. A. Uniforme escolar e uniformização dos corpos. Revista Tempos e Espaços em Educação, v. 10, n. 22, p. 9-22, 2017. DOI:

https://doi.org/10.20952/revtee.v10i22.6134 
ALVES, F. C.; FIALHO, L. M. F.; LIMA, M. S. L. Formação em pesquisa para professores da educação básica. Revista Tempos e Espaços em Educação, v. 11, n. 27, p. 285-300, 2018. DOI: https://doi.org/10.20952/revtee.v11i27.8582

BARDIN, L. Análise de Conteúdo. Lisboa: Edições 70, 1997.

BOGDAN, R.; BLIKEN S. Investigação qualitativa em educação. Porto: Porto Editora, 2017.

BRAZÃO, J. P. G.; OLIVEIRA, A. L.; DIAS, A. F. University students' voices on sexual and gender diversity, their relationship with coeducation and pedagogical innovation: a comparative study at the University of Madeira (Portugal) and the Federal University of Sergipe (Brazil). Journal of Research and Knowledge Spreading, v. 2, n. 1, e12445, 2021. DOI: https://doi.org/10.20952/jrks2112445

BRAZÃO, P. Apresentação do projeto vozes dos estudantes universitários sobre a diversidade sexual e de género, sua relação com a coeducação e com a inovação pedagógica: um estudo comparativo na Universidade da Madeira e na Universidade Federal de Sergipe. The Brain, 2021. Disponível em: https://bra.in/7vA6Q3. Acesso em: 10 out. 2021.

BRAZÃO, P.; DIAS, A. Relações de género e do corpo na Escola: Diretivas promotoras de culturas inclusivas para as práticas pedagógicas. Revista Cocar, v. 14, n. 29, 2020.

BUTLER, J. Problemas de gênero: feminismo e subversão de identidade. 6. ed. Rio de Janeiro: Civilização Brasileira, 2013.

CANAL das Bee. \#GuiaBasicoLGBT. Género não binário. 2018. 1 vídeo (6 min). Disponível em: https://youtu.be/HwmWqtAyj2E. Acesso em: 10 out. 2021.

CARDOSO, H. de M.; DIAS, A. F. Saberes trans* em universidades nordestinas. Revista on line de Política e Gestão Educacional, Araraquara, v. 24, n. Esp. 3, p. 1689-1712, 2020. DOI: https://doi.org/10.22633/rpge.v24i3.14208

CARDOSO, H. M.; DIAS, A. F. Representações sobre corpo, gênero e sexualidades de estudantes das licenciaturas do Instituto Federal de Sergipe, campus Aracaju. Práxis

Educacional, v. 13, n. 24, p. 76-94, 2017. DOI: https://doi.org/10.22481/praxis.v13i24.930

CARDOSO, H. M.; DIAS, A. F. Trans* subjectivities in the higher education curriculum. Journal of Research and Knowledge Spreading, v. 2, n. 1, e12305, 2021. https://doi.org/10.20952/jrks2112305

CARDOSO, L. R.; MELO, R. V. O. S. Construção do critério gênero no Programa Nacional do Livro Didático (2006-2020). Revista Ibero-Americana de Estudos em Educação, v. 16, n. 1, p. 63-83, 2021. DOI: https://doi.org/10.21723/riaee.v16i1.13752

CARDOSO, L. R.; BERTOLDO, T. A. T.; SANTOS, L. B. A. Gênero e sexualidade na formação docente: um mapeamento das pesquisas entre Norte e Nordeste. Revista on line de Política e Gestão Educacional, v. 24, n. esp. 3, p. 1743-1764, 2020. DOI: https://doi.org/10.22633/rpge.v24iesp3.14092 
CARVALHO, M. E. P. et al. Origins and challenges of gender studies centers in higher education in NorthERN and Northeastern Brazil. Revista Tempos e Espaços em Educação, v. 10, n. 21, p. 163-176, 2017. DOI: https://doi.org/10.20952/revtee.v10i21.6340

COUTO, A. S.; CRUZ, M. H. S. Inserção de gênero no currículo de História e a formação para o trabalho docente. Revista Tempos e Espaços em Educação, v. 10, n. 23, p. 249-262, 2017. DOI: https://doi.org/10.20952/revtee.v10i23.6764

CROCIARI, A.; PEREZ, M. C. A. O que estamos estudando sobre gênero na educação infantil: as lacunas na formação docente. Revista Ibero-Americana de Estudos em Educação, Araraquara, v. 14, n. esp. 2, p. 1556-1568, 2019. DOI: https://doi.org/10.21723/riaee.v14iesp.2.12615

DIAS, A. F. et al. Schooling and subversions of gender. Revista Tempos e Espaços em Educação, v. 10, n. 22, p. 83-92, 2017. DOI: https://doi.org/10.20952/revtee.v10i22.6433

DIAS, A. F.; BRAZÃO, J. P. G. Iniciativas de promoção das discussões de gênero e diversidade sexual no contexto acadêmico: um estudo comparativo. Práxis Educacional, v. 17, n. 48, p. 1-18, 2021. Disponível em:

https://periodicos2.uesb.br/index.php/praxis/article/view/9502. Acesso em: 17 set. 2021.

DIAS, A. F.; MENEZES, C. A. A. Que inovação pedagógica a pedagogia queer propõe ao currículo escolar?. Revista Tempos e Espaços em Educação, v. 10, n. 23, p. 37-48, 2017. DOI: https://doi.org/10.20952/revtee.v10i23.7443

DIAS, A. F.; SILVA, I. P. ; RIOS, P. P. S. Os estudos de gênero em revistas científicas do FEPAE-NN: uma revisão sistematizada. Revista Exitus, v. 10, n. 1, p. e020039, 2020. DOI: https://doi.org/10.24065/2237-9460.2020v10n0ID128

DONATO, A.; TONELLI, L. A resistência do corpo. Revista Tempos e Espaços em Educação, v. 12, n. 28, p. 49-62, 2019. DOI: https://doi.org/10.20952/revtee.v12i28.10164

FELICETTI, V. L. et al. Perspectivas emergentes en investigación educativa. Revista Tempos e Espaços em Educação, v. 12, n. 30, p. 155-170, 2019. DOI:

https://doi.org/10.20952/revtee.v12i30.10681

FRANÇA, F. G. R.; FERRARI, A. Mais do que professores/as, professores/as homossexuais na escola. Revista Tempos e Espaços em Educação, v. 9, n. 20, p. 41-52, 2016. DOI: https://doi.org/10.20952/revtee.v9i20.5894

LEMOS, P.; ANDRADE, A.; CARDOSO, B. Subvertendo gênero: o lugar da não-binaridade numa análise discursiva de "blogs". Revista Psicologia, Diversidade e Saúde, v. 9, n. 3, p. 314-326. 2020. DOI: http://dx.doi.org/10.17267/2317-3394rpds.v9i3.3132

LUCIFORA, C. A. et al. Marcas sociais de nossos tempos: gênero, sexualidade e educação em âmbito escolar. Revista Ibero-Americana de Estudos em Educação, Araraquara, v. 14, n. esp. 2, p. 1395-1409, 2019. DOI: https://doi.org/10.21723/riaee.v14iesp.2.12607 
MAFRA, J. R. S.; SÁ, P. F. Abordagens na pesquisa em educação Matemática: algumas reflexões e perspectivas epistemológicas. Revista Tempos e Espaços em Educação, v. 13, n. 32, p. 1-21, 2020. DOI: https://doi.org/10.20952/revtee.v13i32.13465

MEDEIROS, E. A.; AGUIAR, A. L. O. O método (auto) biográfico e de histórias de vida: reflexões teórico-metodológicas a partir da pesquisa em educação. Revista Tempos e Espaços em Educação, v. 11, n. 27, p. 149-166, 2018. DOI: https://doi.org/10.20952/revtee.v11i27.7884

MENEZES, C. A. A.; DIAS, A. F.; SANTOS, M. S. What pedagogical innovation does queer pedagogy propose to the school curriculum?. Práxis Educacional, v. 16, n. 37, p. 241-258, 2020. DOI: DOI: https://doi.org/10.22481/praxisedu.v16i37.6168

MORAIS, J. F. S.; BAIÃO, J. C.; DE FREITAS, C. J. Questões de gênero e sexualidade na escola: narrativas docentes. Revista Tempos e Espaços em Educação, v. 13, n. 32, p. 1-15, 2020. DOI: https://doi.org/10.20952/revtee.v13i32.11565

NASCIMENTO, L. F.; CAVALCANTE, M. M. D. Abordagem quantitativa na pesquisa em educação: investigações no cotidiano escolar. Revista Tempos e Espaços em Educação, v. 11, n. 25, p. 249-260, 2018. DOI: https://doi.org/10.20952/revtee.v11i25.7075

NUNES, C. P. Conversas interativo-provocativas como opção teórico-metodológica nas Ciências Humanas e na educação. Práxis Educacional, v. 16, n. 37, p. 408-439, 2020. DOI: https://doi.org/10.22481/praxisedu.v16i37.6207

OLIVEIRA, A. L.; BRAZÃO, J. P. G.; DIAS, A. F. Dialogue about gender, sexuality and bodies in academic context: a possibility of pedagogical innovation? Journal of Research and Knowledge Spreading, v. 2, n. 1, e12484, 2021. DOI:

https://doi.org/10.20952/jrks2112484

PALMEIRA, L. L. L.; DIAS, A. F. The importance of Teacher education in the face of the perspectives of diversity: in search of an egalitarian society. Journal of Research and Knowledge Spreading, v. 2, n. 1, e12260, 2021. DOI: https://doi.org/10.20952/jrks2112260

PIRES, M. A. Gênero e sexualidade nos currículos de formação em Pedagogia na Universidade Federal de Sergipe. 2021. Dissertação (Mestrado em Educação) Universidade Federal de Sergipe, São Cristóvão, 2021.

PORTUGAL. D.R. 1. ${ }^{\text {a }}$ série N..$^{0}$ 97. Resolução do Conselho de Ministros n. ${ }^{\circ}$ 61/2018, de 21 de maio. Estratégia Nacional para a Igualdade e a Não Discriminação 2018-2030 "Portugal + Igual", XXI Governo Constitucional. 8 mar. 2018. Disponível em: https://dre.pt/application/file/a/115360102. Acesso em: 10 jul. 2021.

RIOS, P. P. S.; CARDOSO, H. M.; DIAS, A. F. Concepções de gênero e sexualidade d@s docentes do curso de licenciatura em pedagogia: por um currículo Queer. Educação \& Formação, v. 3, n. 2, p. 98-117, 2018. DOI: https://doi.org/10.25053/redufor.v3i8.272

RIOS, P. P. S.; DIAS, A. F. "Nossa história de vida é construída a partir do nosso corpo": a produção do corpo viado na docência. Revista Ibero-Americana de Estudos em Educação, Araraquara, v. 15, n. 3, p. 1265-1283, 2020. DOI: https://doi.org/10.21723/riaee.v15i3 
RIOS, P. P. S.; VIEIRA, A. R. L. The emerging of a gender discourse in education: the differences in the school space. Revista Tempos e Espaços em Educação, v. 13, n. 32, p. 118, 2020. DOI: https://doi.org/10.20952/revtee.v13i32.13061

ROCHA, C. J. T.; MALHEIRO, J. M. S. Narrativas identitárias em experiência de transformação e desenvolvimento profissional docente. Revista Ibero-Americana de Estudos em Educação, v. 14, n. 3, p. 986-1000, 2019. DOI:

https://doi.org/10.21723/riaee.v14i3.11836

SANTOS, A. C.; FELDENS, D. G. Vozes do triunfo: narrativas de si de professoras da educação básica. Revista Tempos e Espaços em Educação, v. 11, n. 1, p. 379-392, 2019. DOI: https://doi.org/10.20952/revtee.v11i01.9666

SANTOS, É. S.; LAGE, A. C. Gênero e diversidade sexual na educação básica: um olhar sobre o componente curricular Direitos Humanos e Cidadania da rede de ensino de Pernambuco. Revista Tempos e Espaços em Educação, v. 10, n. 22, p. 69-82, 2017. DOI: DOI: https://doi.org/10.20952/revtee.v10i22.6042

SANTOS, M. H. S. R.; RIOS, J. A. V. P. Education and cultural differences: boundary educational practices in basic education. Revista Tempos e Espaços em Educação, v. 14, n. 33, p. e13670, 27 fev. 2021. DOI: https://doi.org/10.20952/revtee.v14i33.13670

SCOTT, J. O enigma da igualdade. Estudos Feministas, Florianopolis, v. 13, n. 1, p. 216, jan./abr. 2005.

SILVA, I. P.; DIAS, A. F.; RIOS, P. P. S. Os estudos de Gênero na Revista Tempos e Espaços em Educação: uma Revisão Sistematizada. Educação \& Formação, v. 5, n. 14, p. 150-175, 2020. DOI: https://doi.org/10.25053/redufor.v5i14mai/ago.2495

VILAÇA, T. Metodologias de ensino na educação em sexualidade: desafios para a formação contínua. Revista Ibero-Americana de Estudos em Educação, Araraquara, v. 14, n. esp.2, p. 1500-1537, 2019. DOI: https://doi.org/10.21723/riaee.v14iesp.2.12614

VIVAS, A.; BASTIDAS, C.; FARIAS, A. Desempenho acadêmico de uma perspectiva geográfica e de gênero em programas de distância. Revista on line de Política e Gestão Educacional, Araraquara, v. 24, n. 3, p. 1200-1215, 2020. DOI:

https://doi.org/10.22633/rpge.v24i3.14357 


\section{Como referenciar este artigo}

BRAZÃO, J. P. G.; DIAS, A. F. O que dizem os estudantes sobre gênero não-binário: um estudo comparativo na Universidade Federal de Sergipe e na Universiade da Madeira. Revista on line de Política e Gestão Educacional, Araraquara, v. 25, n. 3, p. 2886-2909, set./dez. 2021. e-ISSN:1519-9029. DOI: https://doi.org/10.22633/rpge.v25i3.15680

Submetido em: $15 / 08 / 2021$

Revisões requeridas em: 19/09/2021

Aprovado em: 17/10/2021

Publicado em: 08/12/2021 